\title{
STUDI MANAJEMEN PEMBINAAN OLAHRAGA SEPAK BOLA DI KLUB PERSATUAN SEPAK BOLA KOTA BOGOR OLEH KANTOR PEMUDA DAN OLAHRAGA KOTA BOGOR
}

\author{
Wanda Maulana Haryadi ${ }^{1}$, Ginung Pratidina ${ }^{2}$, M. YGG. Seran ${ }^{3}$ \\ ${ }^{1}$ Jurusan Ilmu Administrasi Negara Fakultas Imu Sosial dan Ilmu Politik Universitas Djuanda, Jl.Tol \\ Ciawi No 1, Kotak Pos 35 Bogor 16770 \\ ${ }^{2}$ Jurusan Ilmu Administrasi Negara Fakultas Imu Sosial dan Ilmu Politik Universitas Djuanda, Jl.Tol \\ Ciawi No 1, Kotak Pos 35 Bogor 16770 \\ ${ }^{3}$ Jurusan Ilmu Administrasi Negara Fakultas Imu Sosial dan Ilmu Politik Universitas Djuanda, Jl.Tol \\ Ciawi No 1, Kotak Pos 35 Bogor 16770
}

(Diterima oleh Dewan Redaksi: 01-02-2016)

(Dipublikasikan oleh Dewan Redaksi: 01-04-2016 )

\begin{abstract}
Wanda Maulana Haryadi, especially Bogor Conditions Soccer Football Association Bogor very loved by the citizens of Bogor, now the condition is worrying. Based on data from the past two years PSB Bogor City almost always experience a downgrade in the league competition held by the Football Association of the city of Bogor.

Factors affecting the achievement at the club include a lack of sports facilities, trainers, motivation, how to train, budget, moral support. It is no less important to note is the election strategy for football coaching at the club so that the Football Association of Bogor able to perform again.

Barriers - barriers to the implementation of the Management Development of Football in the Club Football Association Bogor Based on information from the Head Chairman, Coach, and The Visitor Sport of the tabulation of data questionnaire found a number of factors which may be cited as barriers to the implementation of coaching in order to Management Coaching Football in Clubs Football Association of Bogor others as follows: (1) a lack or weakness of Infrastructures, funding and coaches in clubs PSB (2) for the factors inhibiting the Management coaching is that implementing Management coaching is still recognized the respondent adds to costs Athletes football this an interpretation of the scoring interpretation lowest figure with a score of 2:21 yangberarti Not Good.

(1) Factors inhibiting Management coaching is a lack of facilities and infrastructure and completeness Sports fulfilled. (2) Inhibiting athletic performance is that the implementation of the guidance by Club Football Association Bogor weak in attention and meningatkan that athletes always achievement in football matches (3) efforts to solve the bottleneck problem and factor in coaching athletes football is by tersediannya facilities, infrastructure and completeness Sports fulfilled (4) efforts to address the problem of weak settlement of coaching athletes within the time set by Klub football Association of Bogor in reaching the champions necessary adannya additional fees for athletes who are able to earn achievements (champions)
\end{abstract}

Keywords: Management, Development, Youth and Sports Office. 


\begin{abstract}
ABSTRAK
Kondisi Sepak Bola Bogor khusunya Persatuan Sepak Bola Bogor yang sangat di cintai oleh warga bogor, sekarang kondisinya memprihatikan . Berdasarkan data dua tahun terakhir PSB Kota Bogor hampir selalu mengalami penurunan peringkat pada klasemen kompetisi yang diadakan oleh Persatuan Sepak Bola Kota Bogor.

Faktor yang mempengaruhi prestasi padaklub tersebut antara lain tidak adanya sarana olahraga, pelatih, motivasi, cara melatih, anggaran, dukungan moral. Hal yang tidak kalah penting untuk diperhatikan adalah adanya pemilihan strategi pembinaan olahraga sepak bola pada klub tersebut sehingga Persatuan Sepak Bola Kota Bogor mampu berprestasi lagi.

Hambatan - hambatan pelaksanaan Manajemen Pembinaan Sepak bola di Klub Persatuan Sepakbola Bogor Berdasarkan informasi dari Kepala Ketua Umum, Pelatih, dan Para Pengunjung Olahraga dari hasil tabulasi data penyebaran angket ditemukan sejumlah faktor yang dapat disebut sebagai hambatan pelaksanaan pembinaan dalam rangka Manajemen Pembinaan Sepak bola di Klub Persatuan Sepakbola Bogor lain sebagi berikut :(1)Kurangnnya atau lemahnya Sarana dan Prasarana, dana dan para pelatih yang ada di Klub PSB(2)Untuk faktor penghambat Manajemen pembinaan adalah bahwa melaksanakan Manajemen pembinaan masih diakui responden menambah beban biaya Atlet sepak bola hal ini merupakan perolehan angka penafsiran angka penafsiran terendah dengan skor 2.21 yangberarti Tidak Baik.

(1)Faktor penghambat Manajemen pembinaan adalah Kurangnya Sarana dan prasarana dan kelengkapan Olahraga yang tercukupi.(2)Penghambat prestasi atlit adalah bahwa pelaksanaan pembinaan oleh Klub Persatuan Sepak Bola Bogor lemah dalam memperhatikan dan meningatkan agar atlit selalu meraih prestasi dalam pertandingan sepak bola(3)Upaya untuk mengatasi masalah hambatan dan faktor dalam pembinaan atlit sepak bola adalah dengan tersediannya sarana, prasarana dan kelengkapan Olahraga yang tercukupi(4)Upaya untuk mengatasi masalah lemahnya penyelesaian pembinaan atlit dalam waktu yang di tetapkan oleh Klub Persatuan Sepak Bola Bogor dalam meraih Juara perlu adannya penambahan honor bagi atlit yang mampu mendapatkan prestasi ( juara )
\end{abstract}

Kata Kunci: Manajemen, Pembinaan, Kantor Pemuda dan Olahraga.

Wanda Maulana Haryadi, 2016, Studi Manajemen Pembinaan Olahraga Sepak Bola di Klub Persatuan Sepak Bola Kota Bogor Oleh Kantor Pemuda dan Olahraga. Jurnal Governansi. 


\section{PENDAHULUAN}

Manajemen merupakan bagian yang tidak terpisahkan dari aktivitas suatu organisasi sebuah klub sepak bola. Manajemen yang dimaksudkan disini adalah sebagai suatu cara untuk melaksanakan suatu program kerja agar sesuai dengan tujuan yang telah direncanakan dan ingin dicapai sebelumnya. Klub sepakbola PSB Kota Bogor merupakan satu tim kebanggaan warga Bogor .

Kondisi Sepak Bola Bogor khusunya Persatuan Sepak Bola Bogor yang sangat di cintai oleh warga bogor, sekarang kondisinya memprihatikan .

Berdasarkan data dua tahun terakhir PSB Kota Bogor hampir selalu mengalami penurunan peringkat pada klasemen kompetisi yang diadakan oleh Persatuan Sepak Bola Kota Bogor.

Faktor yang mempengaruhi prestasi pada klub tersebut antara lain tidak adanya sarana olahraga, pelatih,motivasi, cara melatih, anggaran, dukungan moral. Hal yang tidak kalah penting untuk diperhatikan adalah adanya pemilihan strategi pembinaan olahraga sepakbola pada klub tersebut sehingga Persatuan Sepak Bola Kota Bogormampu berprestasi lagi.

Selain itu Masalah Sepak Bola dari segi perilaku tidak sportif dan kecurangan serta karakter yang negatif. Skandal kecurangan, obat-obatan, kekerasan, saling tidak menghormati dan perilakuperilaku lain yang tidak sportif.

Peranan Manajemen dalam masa sekarang perlu dipelajari secara mendalam karena semakin berkembangnya ilmu pengetahuan yang terus meluas serta kemajuan zaman menuntut manusia untuk terus belajar dan terus berkarya agar tidak tertinggal dan tergerus globalisasi. Dalam bidang manajemen perlunya kerja keras untuk memajukan organisasi agar dapat berjalan rapi dan teratur,yang tentunya diperlukan seorang yang mampu berdedikasi tinggi dan bertanggungjawab dalam kegiatan perencanaan,pengorganisasian,penggerak an, serta pengawasan.

Ada empat cara dalam hal Manajemen yaitu :

- Membuat keputusan biasanya menjadi bagian dari perencanaan karena setiap pilihan dibuat berdasarkan proses penyelesaian setiap rencana.Planning penting karena banyak berperan dalam menggerakan fungsi manajemen yang lain.

- Organizing adalah proses dalam memastikan kebutuhan manusia dan fisik setiap sumber daya tersedia untuk menjalankan rencana dan mencapai tujuan yang berhubungan dengan organisasi. Organizing juga meliputi penugasan setiap aktifitas, membagi pekerjaan ke dalam setiap tugas yang spesifik, dan menentukan siapa yang memiliki hak untuk mengerjakan beberapa tugas.

- Actuating adalah peran manajer untuk mengarahkan pekerja yang sesuai dengan tujuan organisasi. Actuating adalah implementasi rencana, berbeda dari planning dan organizing.

- Controlling, memastikan bahwa kinerja sesuai dengan rencana. Hal ini membandingkan antara kinerja aktual dengan standar yang telah ditentukan. Jika terjadi perbedaan yang signifikan antara kinerja aktual dan yang diharapkan, manajer harus mengambil tindakan yang sifatnya mengoreksi.

Segala aktivitas olahraga sepakbola di tanah air masih sangat memerlukan perhatian dan pembinaan khusus, baik dalam usaha pencarian bibit-bibit yang baru maupun dalam usaha meningkatkan prestasi atlet. Olahraga sepak bola dilakukan tidak hanya semata-mata mengisi waktu senggang atau hanya sekedar memanfaatkan fasilitas yang tersedia. 
Dalam upaya peningkatan prestasi yang telah ditargetkan diperlukan usaha untuk mewujudkan rencana tersebut, dengan program pembinaan atlet secara benar dan tepat. Melalui pedomanpedoman yang berlaku, sehingga apa yang telah diprogramkan akan dapat berhasil sesuai tujuan dan mendapat prestasi yang membanggakan. Dalam upaya peningkatan prestasi olahraga nasional, di- perlukan adanya upaya penggalangan dan peningkatan berbagai potensi yang ada seperti: SDM(Sumber Daya Manusi), sarana dan prasarana dan seluruh potensi yang ada lainya.

Dalam undang-undang Republik Indonesia nomor 3 tahun 2005 tentang sistem keolahragaan nasional disebutkan bahwa olahraga merupakan bagian dari proses dan pencapaian tujuan pembangunan nasional sehingga keberadaan dan peranan olahraga dalam kehiduan bermasyarakat, berbangsa dan bernegara harus ditempatkan pada kedudukan yang jelas dalam sistem hukum nasional.

Dalam usaha pembinaan prestasi olahraga sepak bola, diperlukan unsur pendukung yang sangat vital. Salah satu unsur tersebut membuat program pelatih yang berpendidikan. Pelatih yang berpendidikan adalah pelatih yang memahami dengan baik masalah-masalah yang menyangkut kepelatihan, sebuah klub akan mempunyai peluang yang jauh lebih besar untuk berhasil dan berprestasi dari pada klub yang tidak menggunakan pelatih yang tidak mempunyai dasar dalam ilmu kepelatihan. Selain latihan keterampilan dan teknik bermain, yang perlu diperhatikan juga adalah latihan fisik. Latihan dapat dilakukan sendiri atau terkoordinasi dalam sebuah klub atau pusat pelatihan. Kondisi fisik adalah satu kesatuan utuh dari komponen-komponen yang tidak dapat dipisah-pisahkan, baik peningkatannya maupun pemeliharaannya, artinya dalam usaha peningkatan kondisi fisik harus mengembangkan semua komponen tersebut.

\section{MATERI DAN METODE}

Guna mewujudkan Atlet Berprestasi dalam hal olahraga sepak bola.Metode Penelitian yang digunakan dalam penelitian ini adalah metode penelitian kuantitatif. Menurut Sugiyono (2009:10) Metode Penelitian kuantitatif, dinamakan metode tradisional, kareana metode ini sudah cukup lama digunakan sehingga sudah mentradisi sebagai metode untuk penelitian. Metode ini disebut sebagai metode positivistic karena berlandaskan pada filsafat positivisme. Metode ini sebagai metode ilmiah karena telah memenuhi kaidah-kaidah ilmiah yaitu kongrit/empiris, objektif, terukur, rasional dan sistematis. Metode ini juga disebut metode discovery, karena dengan metode ini dapat ditemukan dan dikembangkan berbagai iptek baru. Metode ini disebut metode kuantitatif karena data penelitian berupa angka-angka dan analisis menggunakan statistic.

\section{Populasi dan sampel}

penelitian. Populasi yang ada pada lokus penelitian ini yaitu:

a) JajaranManagemen =2orang

b)Jajarankorppelatih = 2orang

c) JajaranPemain = 14orang

d)JajaranManagementklub $=20$ orang

\section{Jumlah 38 orang}

\section{Sampel}

Bila populasi besar, dan peneliti tidak mungkin mempelajari semua yang ada populasi, misal karena keterbatasan dana, tenaga, waktu, maka peneliti dapat menggunakan sampel yang diambil dari populasi itu. Sampel penelitian ini adalah

1. Sebagian Jajaran Klub Persatuan Sepak Bola Bogor yang berjumlah 380rang. 
Jumlah sampel tersebut didapat berdasarkan penarikan sampel melalui teknik stratifield random sampling yaitu teknik digunakan bila populasi mempunyai anggota/unsur yang tidak homogennya dan berstrata secara proporsional Sugiyono,2009). Untuk menentukan jumlah sampel digunakan rumus Yamane ( Sukandarrumidi, 2012: 56 )

Berdasarkan rumus Yamane jika populasi 38, maka didapat sampel sebagai berikut :

$$
\mathrm{n}=\frac{\mathrm{N}}{\mathrm{N} d^{2}+1}
$$

Keterangan:

$\mathrm{n}$ = Jumlah Sampel

$\mathrm{N}=$ Jumlah Populasi

$\mathrm{d}=$ Presisi ditetapkan $10 \%$

$$
n 1=\frac{38}{38 \times 0.01+1}=\frac{38}{1,38}=27
$$

Jadi sampel yang diperoleh dari populasi 38 dan sampel yang di dapat 27.

\section{TEKHNIK ANALISIS DATA}

Selanjutnya dalam melakukan analisis data menurut Arikunto ( 2006 :224) sebagai berikut :

- Persiapan melalui kegiatan :

a. Mengecek nama dan kelengkapan identitas pengisian kuesioner.

b. Mengecek kelengkapan data, artinya memeriksa isi instrument pengumpulan data (termasuk di dalamnya kelengkapan lembaran instrument barang kali ada yang terlepas atas salah).

- Tabulasi meliputi kegiatan :

a. Memberikan skor terhadap itemitem pertanyaan yang telah dijawab responden.

b. Menghitung distribusi frekwensi dari setiap kategori jawaban yang diberikan oleh responden.

c. Berdasarkan distribusi frekwensi tersebut maka dihitung kriteria penafsiran dari setiap kategori jawaban.

d. Penerapan data sesuai dengan pendekatan penelitian yaitu mengolah data yang diperoleh dengan menggunakan aturan yang ada sesuai dengan pendekatan atau desain penelitian

\section{HASIL DAN PEMBAHASAN}

Tanggapan responden tentang pelaksanaan Manajemen Pembinaan dapat diakumulasikan seperti terlihat dalam tabel sebagai berikut:

Tabel 1

rekapitulasi tanggapan respondententang pelaksanaan Manajemen pembinaan dapat

\begin{tabular}{|c|c|c|c|}
\hline No & Dimensi & Skor & Kriteria \\
\hline 1 & 2 & 3 & 4 \\
\hline 1. & Planing & $13,6 / 6=2,26$ & $\begin{array}{l}\text { Tidak } \\
\text { Baik }\end{array}$ \\
\hline 2. & Organizing & $17,28 / 8=2,16$ & $\begin{array}{l}\text { Tidak } \\
\text { Baik }\end{array}$ \\
\hline 3. & Actuating & $15,04 / 6=2,50$ & Baik \\
\hline 4. & Controling & $12,48 / 4=3,12$ & $\begin{array}{l}\text { Tidak } \\
\text { Baik }\end{array}$ \\
\hline \multirow{2}{*}{\multicolumn{2}{|c|}{$\begin{array}{l}\text { Jumlah } \\
\mathrm{M}=\sum \text { skor/jumlah } \\
\text { indikator }\end{array}$}} & $10,04 / 4$ & \\
\hline & & 2,51 & $\begin{array}{c}\text { Tidak } \\
\text { Baik }\end{array}$ \\
\hline
\end{tabular}
diakumulasikan dalam 4 Metode

Berdasarkan rekapitulasi tanggapan responden tentang pelaksanaan Studi Manajemen Pembinaan Sepakbola di Klub Persatuan Sepakbola Bogordapat simpulkan bahwa pada umumnya pelaksanaan Manajemen Pembinaan sudah berkeseusuaian dengan perolehan angka penafsiran sebesar 2.32 yang berarti Tidak Baik. 


\section{KESIMPULAN DAN IMPLIKASI}

Dapat diambil kesimpulan kesimpulan sebagai berikut :

1. Berdasarkan rekapitulasi tanggapan responden tentang pelaksanaan Manajemen Pembinaan Sepakbola di Klub Persatuan Sepak bola Bogor dapat simpulkan bahwa pada umumnya pelaksanaan Manajemen Pembinaan sudah berkeseusuaian dengan perolehan angka penafsiran sebesar 2.21 yang berarti Tidak Baik. Karena hasil yang saya lihat di klub manajemen pembinaan sepak bola bogor memang benar adanya seperti itu yang ada dalam kuisoner karena manajemen pembinaanya terhambat dari segi dana, pelatih, pemain berprestasi dan sarana dan prasarana.

2. Planning manajemen pembinaan olahraga di klub persatuan sepak bola bogor tidak baik dikarenakan planning yang belum Maksimal yang dilakukan oleh klub persatuan sepak bola bogor.

3. Organizing yang belum sepenuhnya terpenuhi dari segi manajemennya

4. Actuating peran manajer yang tidak untuk mengarahkan para pelatih dan atlit dalam hal planning dan organisasi.

5. Controllingrencana yang dilakukan oleh perstuan sepak bola bogor belum maksimal.

6. Faktor penghambat Manajemen pembinaan adalah Kurangnya Sarana dan prasarana dan kelengkapan Olahraga yang tercukupi.

7. Hambatan yang dialami dalam prestasi atlit adalah manajemennya yang kurang baik dan semua dana yang di butuhkan dan sarana dan prasaran yang ada kurang memadai.

\section{Saran}

1. Manajemen Klub Sepakbola Persatuan Sepak Bola Bogor masih perlu pembenahan dan ditingkatkan khususnya dalam hal keterbukaan manajemen keuangan,sarana dan prasarana untuk meningkatkan kepercayaan masyarakat terhadap manajemen yang pada akhirnya akan meningkat pula dukungan masyarakat terhadap Persatuan Sepak Bola Bogor guna tercapainya prestasi yang lebih baik pada masa yang akan datang.

2. Pembinaan serta kompetisi Persatuan Sepak Bola Bogor perlu lebih ditingkatkan lagi sehingga kesinambungan regenerasi, serta ketersediaan pemain berkualitas sebagai pemain inti tim PSB lebih terjamin, disampingitu dalam penetapan skuad pemain agar diserahkan sepenuhnya kepada pelatih. Diperlukan juga adanya peningkatan dan pembenahan..

\section{DAFTAR PUSTAKA}

Dirham, 1986 Kepemimpinan Organisasasi dan Admnistrasi Olahraga. Semarang : IKIP Semarang

Hani Handoko. T, 1984 Manajemen Personalia dan Sumberdaya Manusia. Yogyakarta : BPEE Arikunto ( 2006 :224)

( Sugiyono,2009)

(Sukandarrumidi, 2012:56) 